А. В. ЛОСЬ ${ }^{1}$, В. Ф. ШМЫРЕВ ${ }^{1}$, В. И. РЯБКОВ ${ }^{2}$

${ }^{1}$ Государственное предприятие «Антонов», Киев, Украина

${ }^{2}$ Национальный аэрокосмический университет им. Н. Е. Жуковского «Харьковский авиационный институт", Харьков, Украина

\title{
ДОСТИЖЕНИЕ ПРЕИМУЩЕСТВА АН-188 СРЕДИ ОПЕРАТИВНО-ТАКТИЧЕСКИХ ВОЕННО-ТРАНСПОРТНЫХ САМОЛЕТОВ
}

\begin{abstract}
В ГП «Антонов» созданы уникальные средние оперативно-тактические военно-транспортные самолеты Ан-12 и Ан-70. На основе базового варианта Ан-12 создано несколько модификаџий, которые эксплуатируются во многих странах мира.

На смену Ан-70 пришел Ан-77 с увеличенными грузоподъемностью и часовой производительностью, который по целому ряду основных параметров превосходит конкурентов-аналогов: американского C-130J-30, западно-европейского А400М и японского С-2.

Однако по дальности действия с максимальной загрузкой Ан-77 уступает A400М, а по крейсерской скорости и боевой готовности - C-2.

Для наиболее полного выполнения таких оперативно-тактических задач:

- перевозка личного состава, техники, грузов и средств МТО;

- доставка воинских формирований, техники и грузов в интересах проведения миротворческих или антитеррористических операций;

- перевозка войск, вооружения, военной техники и материальных средств по стратегическим направлениям;

- доставка частей и соединений ВДВ и сухопутных войск в районы боевого предназначения;

- обеспечение перебазирования авиаџионных частей и соединений, а также для обеспечения превосходства по дальности действия с максимальной загрузкой, по крейсерской скорости и боеготовности коллективом ГП «Антонов» создан Ан-188-средний оперативно-тактический самолет укороченного взлета и посадки, который обеспечивает выполнение ряда задач, недоступных даже для С-2.

На начальной стадии проектирования этой модификаџии использованы научные положения «Методологии проектирования модификаџий ВТС с учетом глубоких изменений в крыле и силовой установке». Наиболее важным модификаџионным изменением в самолете Ан-188 является замена ТВД Д-27 на турбовентиляторный CFM LEAP-1A, что позволило повысить грузоподъемность и боеготовность модификации.

Другим важным модификационным изменением является использование дискретной геометрической крутки местных хорд крыла, что приблизило его форму в плане к эллиптической и обеспечило снижение индуктивного сопротивления при заданной подъемной силе. Такое решение может обеспечить увеличение дальности с максимальной загрузкой до 3200 км.

Эти глубокие модификачионные изменения в силовой установке и геометрии крыла позволяют достичь полного превосходства Ан-188 в классе оперативно-тактических ВТС.

В сочетании с Ан-132Д и Ан-178 модификачия Ан-188 может рассматриваться как единая система обеспечения войск военно-транспортными самолетами.
\end{abstract}

Ключевые слова: оперативно-тактический военно-транспортный самолет; модификационнье изменения в силовой установке и крыле.

\section{Введение}

При анализе тенденций развития оперативнотактических ВТС установлено [1-5], что отечественный самолет Ан-77 по основным параметрам превосходит конкурентов-аналогов: американский C-130J-30, западно-европейский A400M и японский C-2.

Однако по дальности действия с полной нагрузкой он уступает А400M, а по крейсерской скорости и боевой готовности - С-2.
Для обеспечения полного превосходства на его базе создан средний военный десантно-транспортный самолет Ан-188, на котором осуществляются:

- перевозка личного состава, техники, грузов и средств МТО;

- доставка воинских формирований, техники и грузов в интересах проведения миротворческих или антитеррористических операций;

- перевозка войск, вооружения, военной техники и материальных средств по стратегическим направлениям; 
- доставка частей и соединений ВДВ и сухопутных войск в районы боевого предназначения;

- обеспечение перебазирования авиационных частей и соединений.

\section{Глубокие модификационные изменения в самолете Ан-188}

Реализация таких функций в самолете Ан-188 осуществлена путем проведения глубоких изменений в силовой установке и геометрии его крыла.

Наиболее важным модификационным изменением в самолете Ан-188 является замена ТВД Д-27 на турбовентиляторный двигатель CFM LEAP - 1A [6] (рис. 1).

Этот двигатель с высокой степенью двухконтурности оснащен электронной системой управления и контроля, обеспечивающей запуск двигателя, регулирование на переходных и стационарных режимах работы, а также его контроль при всех ожидаемых условиях эксплуатации. Двигатель оснащен системой реверса тяги.

По тяговым характеристикам $P_{i}$ двигатель

CFM LEAP-1A превосходит Д-27, что оказывает положительное влияние на высотно-скоростные и взлетно-посадочные характеристики и даже на показатель топливной эффективности модификации. Кроме того, использование в силовой установке четырех турбовентиляторных двигателей сокращает время на подготовку их к полету, что, безусловно, повышает боеготовность этого ВТС.

Другим важным модификационным изменением является использование локальной геометрической крутки местных хорд крыла в трапециевидных консолях (рис. 2).

Задача реализации локальной крутки местных хорд с учетом размещения двигателей решена для этапа предварительного проектирования ради снижения индуктивного сопротивления путем минимизации коэффициента роста индуктивного сопротивления $[7,8]$ :

$$
\mathrm{B}_{\mathrm{c}}\left(\eta, \overline{\mathrm{z}}_{\mathrm{H}}, \bar{\varepsilon}_{\mathrm{i}}\right) \rightarrow \mathrm{B}_{\min }
$$

где $\bar{\varepsilon}_{\mathrm{i}}$ - относительный угол геометрической крутки местных хорд крыла по его размаху.

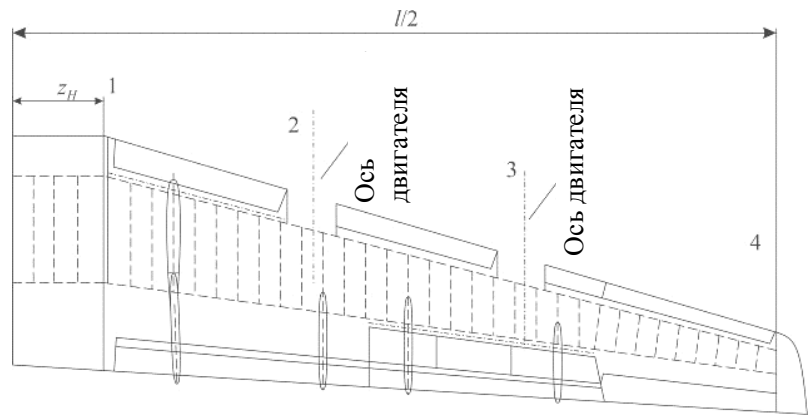

Рис. 2. Схема крыла и размещения двигателей по его размаху

Если учесть, что сужение крыла $\eta$ и координата перехода центроплана в трапециевидную консоль $\overline{\mathrm{z}}_{\mathrm{H}}$ в базовой модели оптимизированы, то добиться снижения коэффициента роста индуктивного сопротивления можно только путем изменения углов геометрической крутки местных хорд по размаху крыла.

В крыле базового самолета оценки $\mathrm{B}_{\mathrm{c}}$ и $\bar{\varepsilon}_{\mathrm{i}}$ определены из необходимой закономерности общей крутки [8] по выражению

$$
\bar{\varepsilon}_{\mathrm{i}}=\frac{2\left[\left(1-\overline{\mathrm{z}}_{\mathrm{H}}\right)+\left(1+\overline{\mathrm{z}}_{\mathrm{H}}\right) \eta_{2}\right]\left(1-\overline{\mathrm{z}}_{\mathrm{H}}\right)\left(1-\overline{\mathrm{z}}_{\mathrm{i}}^{2}\right)^{0,5}}{\pi\left[\eta_{2}-\overline{\mathrm{z}}_{\mathrm{H}}-\left(\eta_{2}-1\right) \overline{\mathrm{z}}_{\mathrm{i}}\right]},
$$

a его линеаризация для полуразмаха крыла Ан-70 изображена на рис. 3.

Как видим, изменение углов установки местных хорд по размаху концевой трапеции $\bar{\varepsilon}_{\mathrm{i}}\left(\overline{\mathrm{z}}_{\mathrm{i}}\right)$ это два участка 1-3 и 3-5 в виде линейного закона их изменения без учета особенностей расположения текущих нервюр, связанных с расположением двигателей на крыле (см. рис. 3).

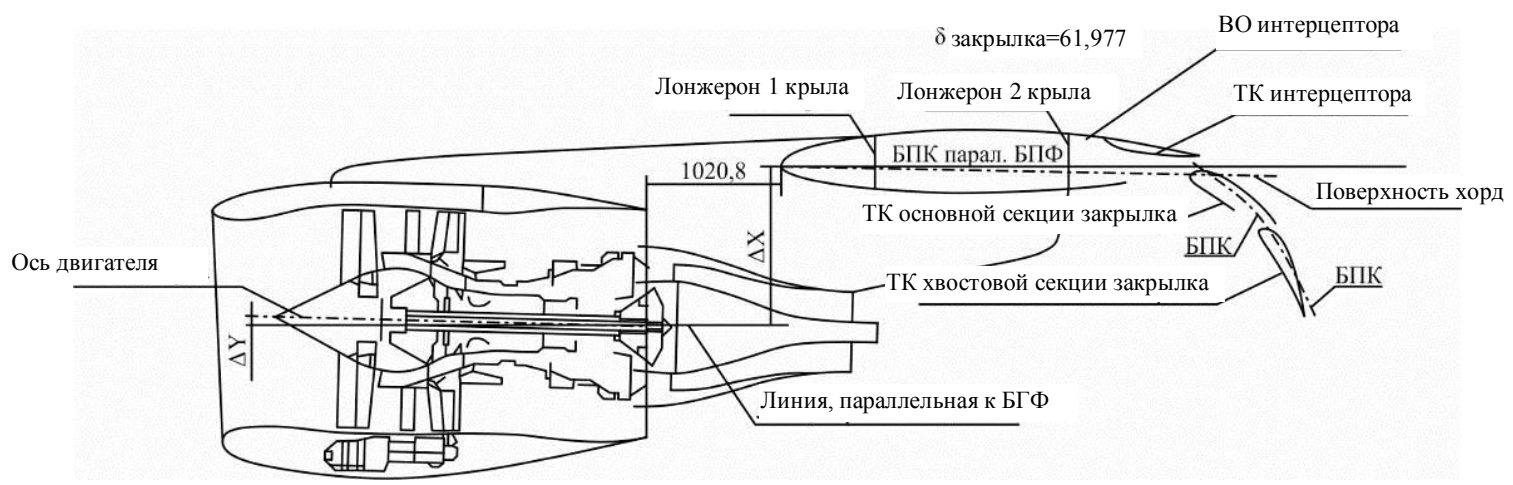

Рис. 1. Компоновка двигателя CFM LEAP-1A на крыле самолета Ан-188 


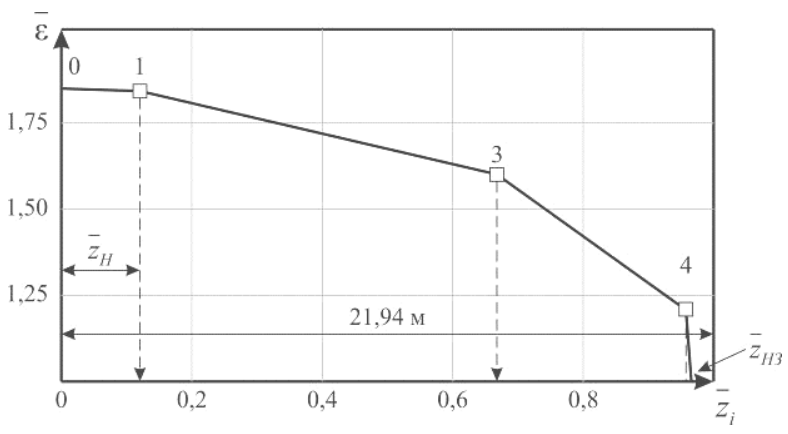

Рис. 3. Значения углов геометрической крутки местных хорд крыла самолета Ан-70 с учетом его аэроупругости

Такая зависимость $\bar{\varepsilon}_{\mathrm{i}}\left(\overline{\mathrm{z}}_{\mathrm{i}}\right)$ не обеспечивает достаточно высокого коэффициента эллиптичности крыла, что и приводит к «недобору» аэродинамического качества.

Учитывая особенность расположения нервюр и навески маршевых двигателей, крыло самолета Ан-188 можно представить в виде условных трапеций на участках 1-2, 2-3, 3-4 (рис. 4), которые принято считать отдельными трапециями с хордами $\mathrm{b}_{1}$, $\mathrm{b}_{2}, \mathrm{~b}_{3}$ и $\mathrm{b}_{4}$, расположенными по размаху при $\overline{\mathrm{z}}_{1}, \overline{\mathrm{z}}_{2}$, $\overline{\mathrm{z}}_{3}$ и $\overline{\mathrm{z}}_{4}$.
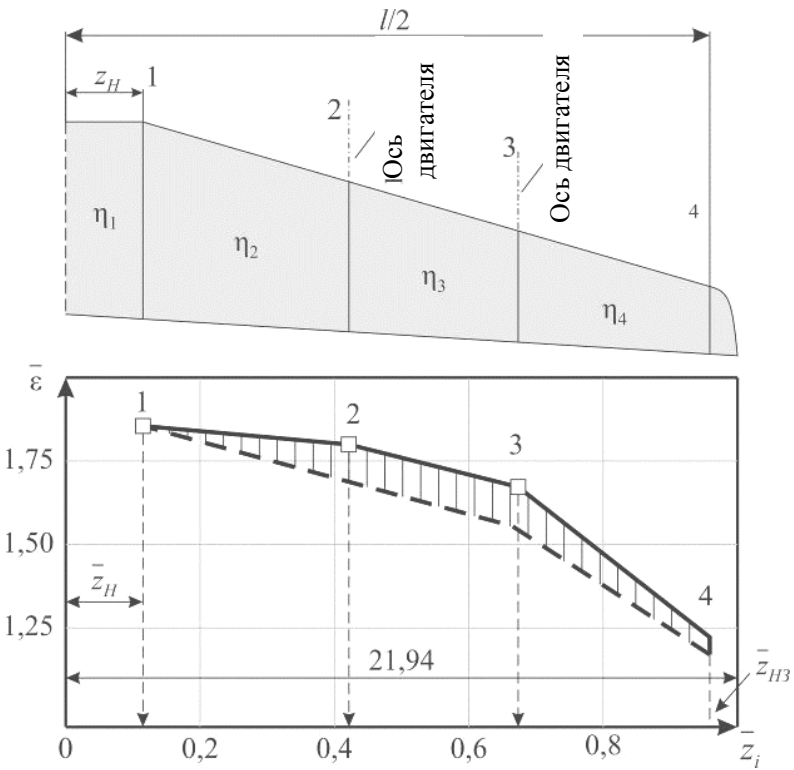

Рис. 4. Линеаризованные значения углов крутки местных хорд крыла самолета Ан-178 по условным трапециям 1-2-3-4, образующим план крыла

При такой схеме углы оптимизирующей крутки местных хорд каждой из условных трапеций можно определять, как для простого трапециевидного крыла на основе зависимости [8]:

$$
\bar{\varepsilon}_{i}=\frac{2\left(\eta_{i}+1\right)}{\pi} \cdot \frac{\left(1-\bar{z}_{i}^{2}\right)^{0,5}}{\eta_{i}-\left(\eta_{i}-1\right) \bar{z}_{i}} .
$$

По предварительным оценкам, использование значений $\bar{\varepsilon}$ (1-2-3-4), полученных на основе дискретной модели, позволяет снизить величину $\mathrm{B}_{\mathrm{c}}$ c 1,039 для базовой модели до 1,01 для модификации, повысить аэродинамическое качество крыла в крейсерском режиме на 0,74 единицы и увеличить дальность действия этой модификации.

Если использовать модели согласования модификационных изменений в силовой установке и крыле [9], то представляется возможным построить одну из основных характеристик ВТС «груз дальность», которая изображена на рис. 5 в абсолютной и сравнительной оценках с А400М и Ан-12.

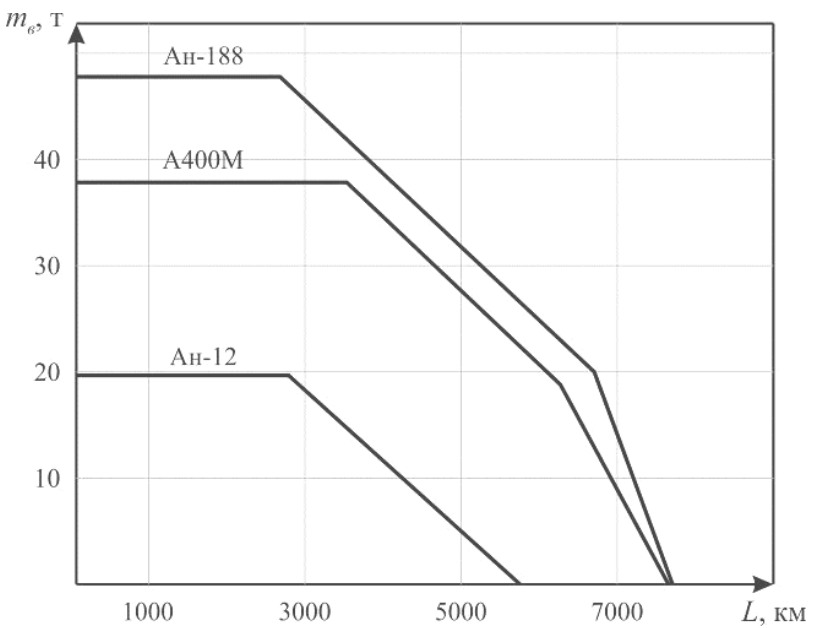

Рис. 5. Сравнительные характеристики «груз -дальность» оперативно-тактических ВТС

Ан-188 превосходит всех конкурентов и по габаритам грузовой кабины (рис. 6). Ни один другой оперативно-тактический ВТС не может перевозить крупногабаритные грузы, как это может делать Ан-188.

Кроме того, при наличии турбовентиляторных двигателей крейсерская скорость Ан-188 несколько увеличена и весьма важный фактор - боеготовность.

Как видим, по дальности действия при $\mathrm{mr}=47 \mathrm{~T}$ Ан-188 несколько уступает А400М, однако при грузоподъемности, максимальной для А400М, Ан-188 превосходит этот европейский оперативно-тактический самолет.

Важной отличительной особенностью Ан-188 является его возможность базирования на аэродромах с грунтовым покрытием в режиме короткого взлета и посадки (КВП) (табл. 1), что существенно расширяет возможности его использования.

Самолет C-2 таких возможностей не имеет, т. к. режим КВП для него недоступен. Грузы в зону боевых действий он может доставлять только в режиме десантирования и не имеет возможности забрать пострадавших непосредственно из зоны экологических катастроф. 

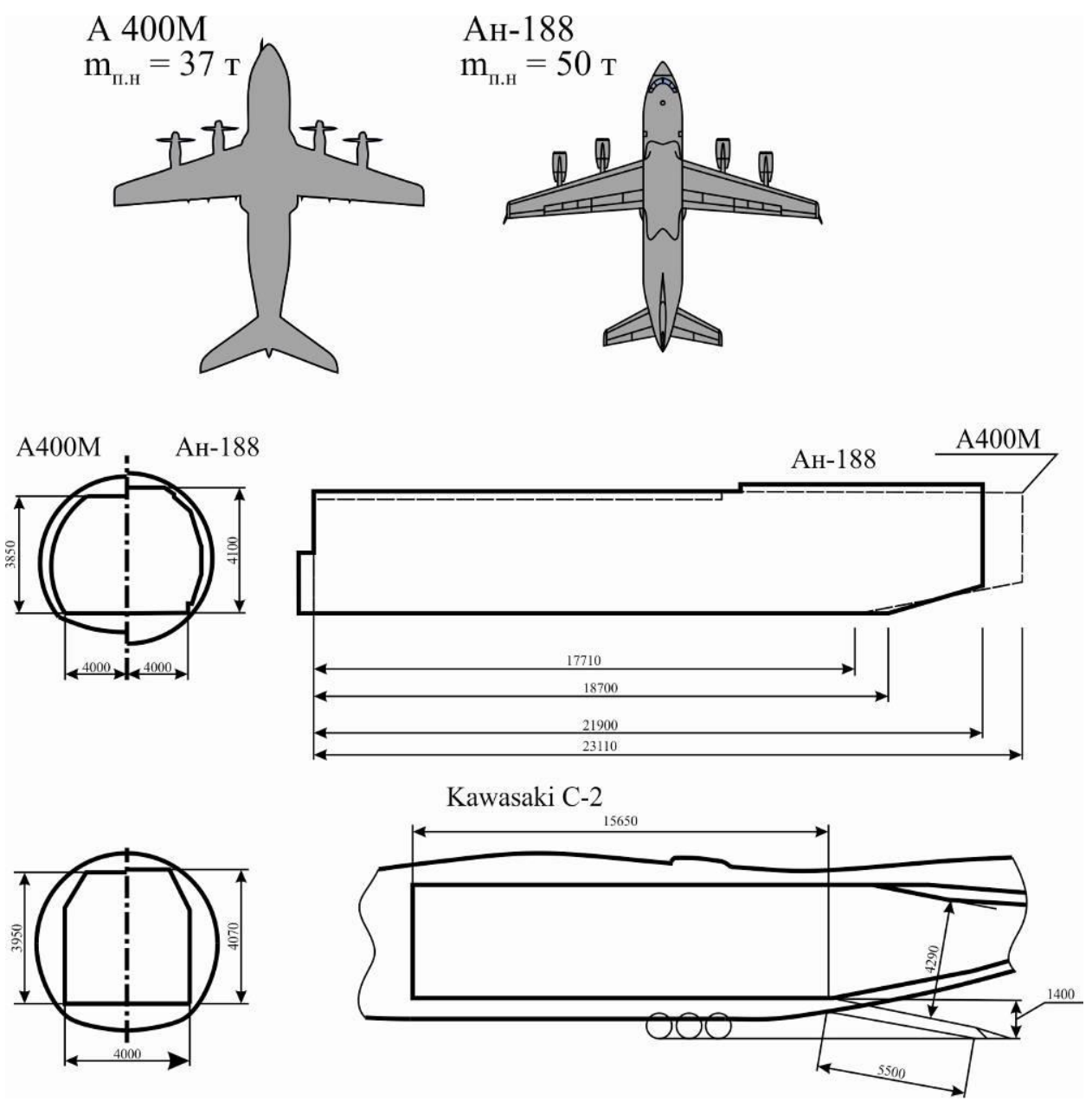

Рис. 6. Размеры грузовых кабин самолета Ан-188 и его конкурентов: А-400 М и С-2

Таблица 1

Параметры Ан-188 в режиме КВП

\begin{tabular}{|c|c|c|}
\hline Наименование характеристики & ОВП & КВП \\
\hline $\begin{array}{l}\text { Двигатели: } \\
\text { - тип }\end{array}$ & \multicolumn{2}{|c|}{$\begin{array}{c}\text { ТРДД } \\
\text { CFM LEAP-1A/1C }\end{array}$} \\
\hline Максимальная взлетная тяга, кгс & \multicolumn{2}{|c|}{$4 \times 14580$} \\
\hline Потребная длина ВПП, м & 1900 & 800 \\
\hline Взлетная масса, т & 145 & 118 \\
\hline $\begin{array}{l}\text { Практическая дальность с грузом, км: } \\
-47 \text { т } \\
-35 \mathrm{~T} \\
-20 \mathrm{~T} \\
- \text { без груза }\left(\mathrm{V}_{\text {кр }}=700 \text { км/ч) }\right.\end{array}$ & $\begin{array}{l}3000 \\
5000 \\
6300 \\
7600\end{array}$ & $\begin{array}{c}- \\
- \\
3800 \\
7600\end{array}$ \\
\hline $\begin{array}{l}\text { Рейсовый расход топлива } \\
(\text { при перевозке } 20 \text { т), кг/ч }\end{array}$ & 4600 & 4350 \\
\hline
\end{tabular}

Из приведенных данных следует, что самолет Ан-188 по грузоподъемности, дальности действия с максимальной загрузкой, рейсовой и часовой производительности, параметрам грузовой кабины и боеготовности превосходит конкурентов-аналогов, т. е. имеет полное превосходство в секторе оперативно-тактических ВТС.

\section{Выводы}

Анализ развития оперативно-тактических военно-транспортных самолетов показал, что отечественный самолет Ан-77 по ряду основных параметров превосходит конкурентов-аналогов: американский C-130J-30, западно-европейский А400M и 
японский C-2. Однако по дальности действия с максимальной загрузкой Ан-77 уступает A400M, a по крейсерской скорости и боевой готовности - C-2.

Для полного выполнения таких оперативнотактических задач:

- перевозка личного состава, техники, грузов и средств МТО;

- доставка воинских формирований, техники и грузов в интересах проведения миротворческих или антитеррористических операций;

- перевозка войск, вооружения, военной техники и материальных средств по стратегическим направлениям;

- доставка частей и соединений ВДВ и сухопутных войск в районы боевого предназначения;

- обеспечение перебазирования авиационных частей и соединений, а также для обеспечения превосходства по дальности действия с максимальной загрузкой, по крейсерской скорости и боеготовности коллективом ГП «Антонов» создан Ан-188средний оперативно-тактический самолет укороченного взлета и посадки, который обеспечивает выполнение ряда задач, недоступных даже для C-2.

На начальной стадии проектирования этой модификации использованы научные положения «Методологии проектирования модификаций ВТС с учетом глубоких изменений в крыле и силовой установке». Наиболее важным модификационным изменением в самолете Ан-188 является замена ТВД Д-27 на турбовентиляторный CFM LEAP-1A, что позволит повысить грузоподъемность и боеготовность модификации.

Другим важным модификационным изменением стало использование дискретной геометрической крутки местных хорд крыла, что приблизило его форму в плане к эллиптической и обеспечило снижение индуктивного сопротивления при заданной подъемной силе.

Такие глубокие модификационные изменения в силовой установке и геометрии крыла способствуют достижению полного превосходства Ан-188 в классе оперативно-тактических ВТС.

В сочетании с Ан-132Д и Ан-178 [11, 12] модификация Ан-188 может рассматриваться как единая система обеспечения войск военнотранспортными самолетами.

\section{Литература}

1. Военно-транспортный самолет Ан-70 [Электронный ресурс]. - Режим доступа: https://www.airport.ru/direktory/aviation/310.html. 12.05.2020.

2. Bombardier forecast 2007-2026 [Электронный ресурс]. - Режим доступа: https://www.bombardier.com. - 12.05.2020.
3. Global Market Forecast. Future Journeys 2013 - 2020 [Electronic resource] /AIRBUS S.A.S Blagnac Cedex: Art @ Caractere, 2013. - 125 p. Available at: http://www.airbus.com/company/market/ forecast/?elD=damfrontend push@docID=33755. 12.05.2020.

4. 747-400 Freighter Main deck cargo arrangements. - Boeing, 2010. - 10 p. [Electronic resource]. Available at: http://www.boeing.com. - 12.05.2020.

5. Анализ мирового рынка средних и стратегических военно-транспортных самолетов в 2001 2010 гг. и на период до 2015 года. [Электронный pесурс]. - М. : ФГУП «Рособоронэкспорт», 2007Режим доступа: http://vpk.name/news. - 12.05.2020.

6. Иностранные авиационные двигатели, 2005 [Текст] : Справочник ЦИАМ. - Вып. 14 ; общ. ред.: В. А. Скибин, В. И. Солонин - М. : Изд. дом «Авиамир», 2005. -592 c.

7. Тюрев, В. В. Методы оценки оптимизирующей крутки крыла в моделях выбора его геометрических параметров [Текст] / В.В. Тюрев, В. В. Утенкова // Открытые информачионные и компьютерные интегрированные технологии : сб. науч. тр. Нац. аэрокосм. ун-та им. Н. Е. Жуковского «ХАИ». - Харьков, 2005. - Bылn. 26. - C. 169-175.

8. Тиняков, Д. В. Анализ форм трапециевидных крыльев по частным критериям их эффективности [Текст] / Д. В. Тиняков, В. В. Утенкова // Авиачионно-космическая техника и технология. - 2012. № 9 (96). - C. 54-60.

9. Лось, А. В. Формирование геометрии системы несущих поверхностей «крыло + агрегаты хвостового оперения» с учетом коэффициента эллиптичности трапециевидного крыла [Текст] / А. В. Лось // Вопросы проектирования и производства конструкиий летательных аппаратов : сб. науч. тр. Нац. аэрокосм. ун-та им. Н. Е. Жуковского «ХАИ». - Харьков, 2019. - Bылn. 4 (96). - C. 84-89.

10. AN-132D Preliminary ground and flight tests first stage [Текст]. Технический aкm № 132D.700.024.Д3-117 ГП «Антонов», 2017. - 72 c.

11. AN-178 High level roaodmap AN-178 [Text]. ГП «Антонов», 2016. - 57 c.

12. Ан-188 Средний военно-транспортный самолет укороченного взлета и посадки [Текст]. ГП «Антонов». - Киев : ГП «Антонов», 2018. $118 \mathrm{c}$.

\section{References}

1. Voenno-transportnyj samolet An-70 [Military transport aircraft An-70]. Available at: https://www.airport.ru/direktory/aviation/310.html. (accessed 12.05.2020).

2. Bombardier forecast 2007 - 2026. Available at: https://www.bombardier.com. (accessed 12.05.2020). 
3. Global Market Forecast. Future Journeys 2013-2020. AIRBUS S.A.S, Blagnac Cedex: Art@ Caractere, 2013. 125 p. Available at: http://www. airbus.com/company/market/forecast/?elD=dam. $\quad($ accessed 12.05.2020).

4. 747-400 Freighter Main deck cargo arrangements. Boeing, 2010. 10 p. Available at: http:// www.boeing.com. (accessed 12.05.2020).

5. Analiz mirovogo rynka srednih i strategicheskih voenno-transportnyh samoletov v 2001-2010 g. g. i na period do 2015 goda [Analysis of the global market for medium and strategic military transport aircraft in $2001-2010$ and for the period until 2015]. Moscow, FGUP «Rosoboronjeksport», 2007. Available at: https://vpk.name/news. (accessed 12.05.2020).

6. Inostrannye aviacionnye dvigateli [Foreign aircraft engines]. Moscow, CIAM reference book ; general edition Skibin, V. A., Solonin, V. I., «Aviamir» Publishing House, 2005, vol. 14. 592 p.

7. Tjurev, V. V., Utenkova, V. V. Metody ocenki optimizirujushhej krutki kryla $\mathrm{v}$ modeljah vybora ego geometricheskih parametrov [Methods for evaluating the optimizing wing twist in models for choosing its geometric parameters]. Open Information and Computer
Integrated Technologies, NAU «KhAI», 2005, vol. 26. pp. 169-175.

8. Tinjakov, D. V., Utenkova, V. V. Analiz form trapecievidnyh kryl'ev po chastnym kriterijam ih jeffektivnosti [Analysis on tapered wing shapes of partial criteria of their effectiveness]. Aviacijno-kosmicna tehnika i tehnologia - Aerospace technic and technology, 2012, vol. 9 (96), pp. 54-60.

9. Los', A. V. Formirovanie geometrii sistemy nesushhih poverhnostej «krylo + agregaty hvostovogo operenija»s uchetom kojefficienta jelliptichnosti trapecievidnogo kryla [Formation of the geometry of the system of bearing surfaces "wing + tail units" taking into account the ellipticity coefficient of the trapezoidal wing]. Issues of design and manufacture of aircraft structures, NAU «KhAI», 2019, vol. 4 (96), pp. 84-89.

10. AN-132D Preliminary ground and flight tests first stage. Technical act no. 132D.700.024.D3-117 SE «Antonov», 2017. $72 \mathrm{p}$.

11. AN-178 High level roaodmap. SE «Antonov», 2016. $57 \mathrm{p}$.

12. AN-188 Srednij voenno-transportnyj samolet ukorochennogo vzleta i posadki [AN-188 medium military transport aircraft with short take-off and landing]. Kiev, SE «Antonov», 2018. 118 p.

Надійшла до редакиії 18.05.2020, розглянута на редколегії 15.08.2020

\section{ДОСЯГНЕННЯ ПЕРЕВАГИ АН-188 СЕРЕД ОПЕРАТИВНО-ТАКТИЧНИХ ВІЙСЬКОВО-ТРАНСПОРТНИХ ЛІТАКІВ}

\section{О. В. Лось, В. Ф. Шмирьов, В. І. Рябков}

На ДП «Антонов» створені унікальні середні оперативно-тактичні військово-транспортні літаки Ан-12 і Ан-70. На основі базового варіанта Ан-12 створено декілька модифікацій, які експлуатуються в багатьох країнах світу.

На заміну Ан-70 створено Ан-77 з більш високою вантажопідйомністю й часовою продуктивністю, який за багатьма основними параметрами перевершує конкурентів-аналогів: американський C-130J-30, західно-європейський А400M і японський С-2.

Однак за дальністю дії з максимальним завантаженням Ан-77 поступається А400M, а за крейсерською швидкістю та бойовою готовністю - C-2.

Для найбільш повного виконання оперативно-тактичних завдань:

- перевезення особового складу, техніки, вантажів і засобів МТЗ;

- доставка військових формувань, техніки й вантажів в інтересах проведення миротворчих або антитерористичних операцій;

- перевезення військ, озброєння, військової техніки й матеріальних засобів у стратегічних напрямах;

- доставка частин і з'єднань ВДВ і сухопутних військ у райони бойового призначення;

- забезпечення перебазування авіаційних частин і з'єднань,

а також для забезпечення переваги за дальністю дії з максимальним завантаженням, за крейсерською швидкістю і боєготовністю колективом ДП «Антонов» створено Ан-188 - середній оперативно-тактичний літак укороченого зльоту й посадки, що забезпечує виконання багатьох завдань, недоступних навіть для С-2.

На початковій стадії проектування цієї модифікації використано наукові положення «Методики проектування модифікацій ВТЛ з урахуванням глибоких змін у крилі й силовій установці». Найбільш важливою модифікаційною зміною в літаку Ан-188 є заміна ТВД Д-27 на турбовентиляторний CFM LEAP-1A, що дало змогу підвищити вантажопідйомність і боєготовність модифікації.

Іншою важливою модифікаційною зміною стало використання дискретної геометричної крутки місцевих хорд крила, що наблизило його форму в плані до еліптичної та забезпечило зниження індуктивного опо- 
ру при заданій піднімальній силі. Таке рішення може забезпечити збільшення дальності з максимальним завантаженням до 3200 км.

Ці глибокі модифікаційні зміни в силовій установці й геометрії крила сприяють досягненню повної переваги Ан-188 у класі оперативно-тактичних ВТЛ.

У поєднанні з Ан-132Д і Ан-178 модифікація Ан-188 може розглядатися як єдина система забезпечення військ військово-транспортними літаками.

Ключові слова: оперативно-тактичний військово-транспортний літак; модифікаційні зміни в силовій установці й крилі.

\section{THE PROVISION OF COMPLETE SUPERIORITY OF TACTICAL MTA An-188}

\section{A. Los, V. Shmyrov, V. Riabkov}

In the "Antonov" Company, a unique medium-sized tactical military transport aircraft An-12 and An-70 have been created. Based on the An-12 basic version, several modifications have been developed, which operate in many countries around the world.

To replace this aircraft has been created the An-70 with a higher capacity and hourly capacity, which on some key parameters outperforms the competition-analogs: American C-130J-30, West-European A400M, and Japanese C-2.

However, the range with the maximum capacity is worse for An-77 compared to the A400M, but cruising speed and combat readiness - for C-2.

For the most complete implementation of tactical tasks:

- transportation of personnel, equipment, goods, and means of procurement;

- delivery of military units, equipment, and cargo in the interests of peacekeeping or counter-terrorism operations;

- transportation of troops, arms, military equipment and material resources of strategic direction;

- delivery of units and formations of the airborne forces and ground forces in the areas of military purpose;

- provision of the relocation of aviation units and formations, and provision of superiority at range with maximum load, at cruising speed and combat readiness the team of the "Antonov" Company created the An-188 - the medium-sized tactical aircraft with short takeoff and landing, which provides execution of a series of tasks, not available even for C-2.

At the initial stage of designing this modification scientific principles the "Design techniques of modifications of the MTA taking into account the profound changes in the wing and the power plant" were used. The most important modification change in An-188 is the replacement of the D-27 turboprop engine for CFM LEAP-1A turbofan engine, which increased the capacity and combat readiness of modification.

Another important modification change was the use of discrete geometric twist of the wing local chord, bringing its shape in plan view to elliptical one and has brought a reduction in induced drag for a given lift force. This solution provided an increase in the range of up to $3200 \mathrm{~km}$.

Such profound modification changes in the power plant and the geometry of the wing have contributed to the complete superiority of the An-188 in the class of operational-tactical MTA.

In combination with An-132D and An-178 modification, the An-188 can be considered as a unified system of support for the troops with military transport planes.

Keywords: operational-tactical military transport aircraft; modification changes in the power plant and wing.

Лось Александр Васильевич - канд. техн. наук, Президент ГП «Антонов», Киев, Украина.

Шмырев Владимир Федорович - канд. техн. наук, Первый Вице-президент ГП «Антонов», Киев, Украина.

Рябков Виктор Иванович - д-р техн. наук, профессор, Национальный аэрокосмический университет им. Н. Е. Жуковского «Харьковский авиационный институт», Харьков, Украина.

Alexander Los - Candidate of Technical Sciences, President of the SE «Antonov», Kiev, Ukraine, e-mail: systems.an@ukr.net, ORCID Author ID: 0000-0002-6636-4208.

Volodymyr Shmyrov - Candidate of Technical Sciences, First Vice President of the SE «Antonov», Kiev, Ukraine, e-mail: smyrov@antonov.com, ORCID Author ID: 0000-0002-2252-2032.

Victor Riabkov - Doctor of Technical Science, Professor of National Aerospace University "Kharkiv Aviation Institute", Kharkiv, Ukraine,

e-mail: v.riabkov@khai.edu, ORCID Author ID: 0000-0001-6512-052X. 